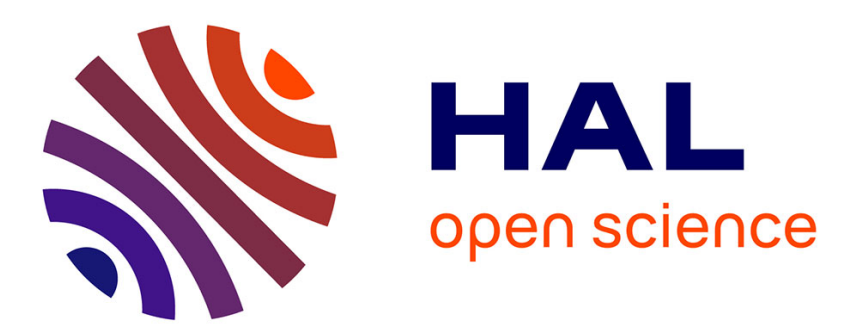

\title{
Testing and modelling the behaviour of steel sheets for roll levelling applications
}

Bruno Dratz, Vincent Nalewajk, Jérôme Bikard, Yvan Chastel

\section{To cite this version:}

Bruno Dratz, Vincent Nalewajk, Jérôme Bikard, Yvan Chastel. Testing and modelling the behaviour of steel sheets for roll levelling applications. 12th ESAFORM Conference on Material Forming, Apr 2009, Enschede, Netherlands. pp.Pages 519-522, 10.1007/s12289-009-0560-3 . hal-00509448

\section{HAL Id: hal-00509448}

https://hal-mines-paristech.archives-ouvertes.fr/hal-00509448

Submitted on 12 Aug 2010

HAL is a multi-disciplinary open access archive for the deposit and dissemination of scientific research documents, whether they are published or not. The documents may come from teaching and research institutions in France or abroad, or from public or private research centers.
L'archive ouverte pluridisciplinaire HAL, est destinée au dépôt et à la diffusion de documents scientifiques de niveau recherche, publiés ou non, émanant des établissements d'enseignement et de recherche français ou étrangers, des laboratoires publics ou privés. 


\title{
TESTING AND MODELLING THE BEHAVIOUR OF STEEL SHEETS FOR ROLL LEVELLING APPLICATIONS
}

\author{
B. DRATZ ${ }^{1,2}$ *, V. NALEWAJK ${ }^{2}$, J. BIKARD $^{1}$, Y. CHASTEL ${ }^{1}$ \\ ${ }^{1}$ Ecole des Mines de Paris-ParisTech, Cemef, UMR 7635, \\ ${ }^{2}$ PSA PEUGEOT CITROEN
}

\begin{abstract}
Three different models are developed to determine the loading modes experienced by the material in roll levelling operations (a finite element approach, an analytical and a semi-analytical model). This study shows that the semi-analytical model is the more appropriate in order to determine the parameters of rolls levellers and the analytic one is sufficient to define the size of the levellers. A specific experimental testing set-up, SOFT (Sheet Oscillatory Flexion Test), has also been designed and used to determine the mechanical response of steel sheets under the different loading modes of the process. The equipment is described and the first results in terms of materials parameters identification are presented, for further analysis and optimisation of roll leveller industrial set-ups.
\end{abstract}

KEYWORDS: Roll levelling, bending, finite element model, elastic-plastic analytical model, thin steel sheet

\section{INTRODUCTION}

With the introduction of new high performance steel grades, efficient and sophisticated techniques of transformations of thin sheet materials are required. Before deep drawing operations, the sheet should be ideally flat and free of residual stresses. The equipment typically devoted to this operation is a roll leveller. In such a set-up, the sheet is bent in alternate directions by means of rollers, as illustrated in figure 1.

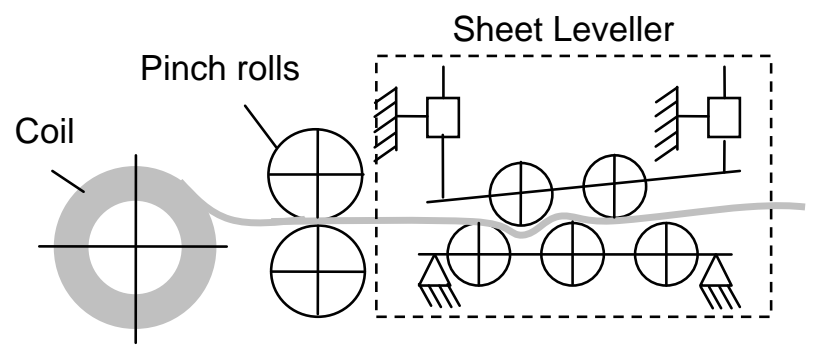

Figure 1: Sheet leveller in the initial process chain

The entrance and exit separation gaps of upper and lower rolls control the shape of the sheet (fig. 1). The entrance gap imposes a curvature and the exit gap adjusts the curvature to zero. Therefore, the regulation and optimisation of the process consist in determining the entrance intermesh value that allows to remove the entrance curvature deviation and the proper exit intermesh for levelling the sheet.

Several studies have analysed this process in order to determine these parameters or to size levellers.
K. Ploetz [1-2] developed a model, based on the discretization in length and thickness. The model determines the contact position between the sheet and the rolls. It allows to predict the residual strain with a 5roll leveller.

E. Doege and co. [3] have implemented a model similar to the previous one. The difference lies in the calculation of the sheet location in between the rolls. The sheet curvature is assumed to match a polynomial of the $3^{\text {rd }}$ and of the $4^{\text {th }}$ degree. This avoids the discretization in length and improves the calculation speed.

K. Park and S. M. Hwang [4] have also used a finite element model of roll levellers. The residual strain distribution, the residual curvature and the forces are obtained from the finite element model.

In the first part of this paper, we present three different models of the levelling process, a finite element model, an analytical and a semi-analytical model. We analyse the quality and the computation times of these models. We conclude with a specific experimental testing set-up which identifies materials behaviour law parameters.

\section{LEVELLING PROCESS MODEL}

\subsection{FINITE ELEMENT MODEL}

The numerical simulation was carried out using a commercial code, FORGE2 ${ }^{\circledR}$ [5]. The simulation is divided into 2 operations. The first operation consists in moving down all the upper rolls with respect to the lower

\footnotetext{
* Ecole des Mines de Paris-ParisTech, Cemef, 06904 Sophia Antipolis, France (e-mail: bruno.dratz@ensmp.fr)
} 
rolls. In the second operation, the sheet starts moving at a constant velocity.

This $2^{\text {nd }}$ operation of the levelling process is the most important one. In the case of this study, all rolls are rotating. In this simulation, the latter boundary condition is represented by imposing a tangential velocity on the nodes of the tool in contact with the sheet.

\subsection{ANALYTICAL MODEL}

Two different analytical models are presented in this section.

\subsubsection{Mechanics of one unit of the levelling process}

The contact zone between a roll and the sheet is very small, so in a first approach we consider it to be pointwise. At these contact points, the rolls exert a punctual force onto the sheet. The resulting bending moment of these force is linear between 2 rolls.

We can link the stress in the material to the moment with the following equation [6]:

$$
M(x)=\int_{-s / 2}^{s / 2} w \sigma(h, x) h d h
$$

where $\mathrm{M}$ is the bending moment, $\mathrm{w}$ is the width, $\sigma$ is the stress and $\mathrm{s}$ is the thickness

If the constitutive law is considered as known, the strain in the sheet and so on the curvature is also known.

\subsubsection{Curvature identification, method 1}

The goal is then to identify the curvature using the previous equation. In this part, we suppose that we know the force of the rolls and the location of the contact point between the rolls and the sheet. In section 2.2.4, we will explain how these parameters are determined.

Firstly, the sheet is discretized along the longitudinal $\mathrm{x}$ coordinate.

An inverse identification of the curvature is used for each $\mathrm{x}$. It means that we suppose that the local curvature of the sheet is known, so we calculate the strain in the sheet. Then, with the behaviour law, the stress is obtained and the bending moment is calculated. Since we also know the force of the rolls, and that the moment must be linear between two rolls, the curvature of the sheet is change until the last constraint is satisfy.

\subsubsection{Curvature identification, method 2}

A second method can also be developed to calculate the curvature of the sheet.

The sheet between two rolls is divided into two parts: one behaving elastically and another one elasticplastically.

Since the moment is linear, the bending line of the elastic part can be described by a polynomial function of the 3rd degree. To calculate the bending line where there is some plastic deformation, a polynomial of the $4^{\text {th }}$ degree is used [5].

In this method, an inverse identification was used. It means that first the transition point has to be known between the elastic and the elastic-plastic zones.
Since the moment on each rolls is known and using the linearity of the moment, the moment can be calculated everywhere. The position of the neutral line for the elastic part can be determined. We then calculate the neutral line for the elastic-plastic part. The polynomial form of the $4^{\text {th }}$ degree has to be linked with the polynomial form of the elastic part in a system of equations and has to be connected with the position of the next roll.

\subsubsection{Contact identification}

In both methods, the contact between the rolls and the sheet is assumed to be known. In fact in the levelling process analysis, it is not known before hand because the sheet must be in contact with the roll and tangent to the roll, these parameters can be obtained through an inverse analysis.

\section{BENDING TEST}

The cyclic behaviour law of materials is determined with a bending-unbending apparatus. This device has been design and built.

\subsection{EXPERIMENT}

Two specimens $(70 \times 5 \mathrm{~mm})$ of sheet metal are used for the test. Each specimen is supported by two grips, separated by a specific distance.

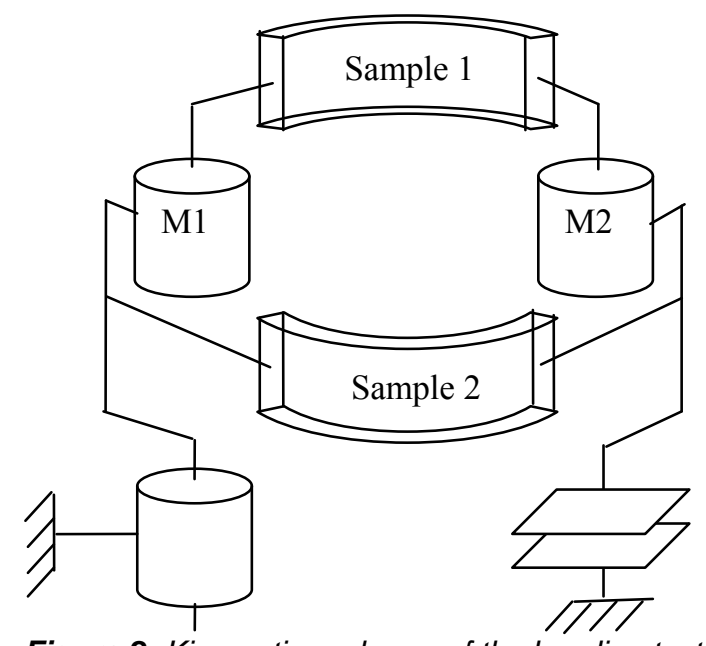

Figure 2: Kinematics scheme of the bending test

The device is equipped with motors (Figure 5), which allow to impose two angles, equal but opposite. The torque is then measured.

The motor M1 is the reference rotation mode. The motor M2 must be able to perform a movement of translation to compensate the variation of distance induced by the inflection of the sample and a movement of opposite rotation with respect to that of the motor M1. A prismatic joint between the reference and M2 could be used but avoid rubber component, another solution has been chosen: the planar joint. M2 is free to get closer or to move away from M1. The perpendicular translation 
along the longitudinal axis of the sample of motors is not set by a link support plan. To set it, a second sample is bent in the opposite direction of the first sample (Figure 6) [7].

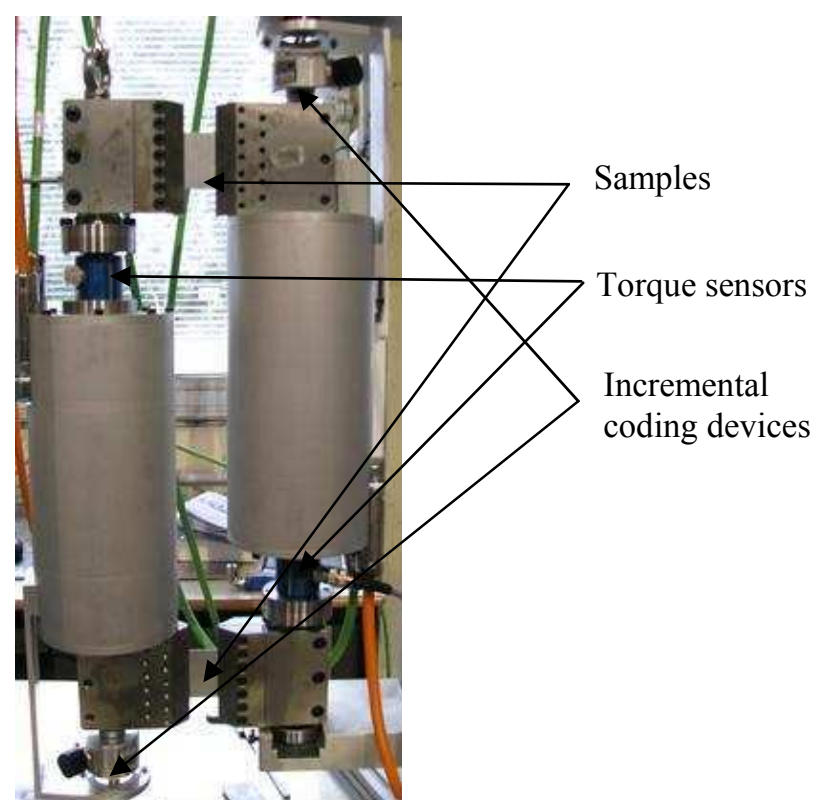

Figure 3: Bending test

The torques are measured with a torque sensor and the curvature can either be determined with a camera or an incremental coding device.

The incremental coding device gives an angle and the curvature of the sheet thanks to the following equation:

$$
\rho=\frac{\theta}{L}
$$

where $\theta=$ curvature angle and $\mathrm{L}=$ length of the sample

The camera provides pictures all along the bending test. The radius of the sheet curve is then calculated after a post treatment of the pictures. This method gives the accurate curvature of the sheet.

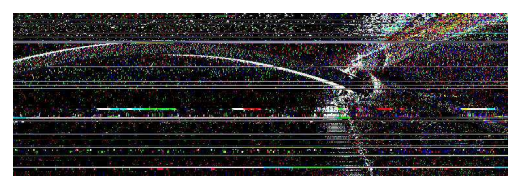

Figure 4: Picture of the sheet in a bending test

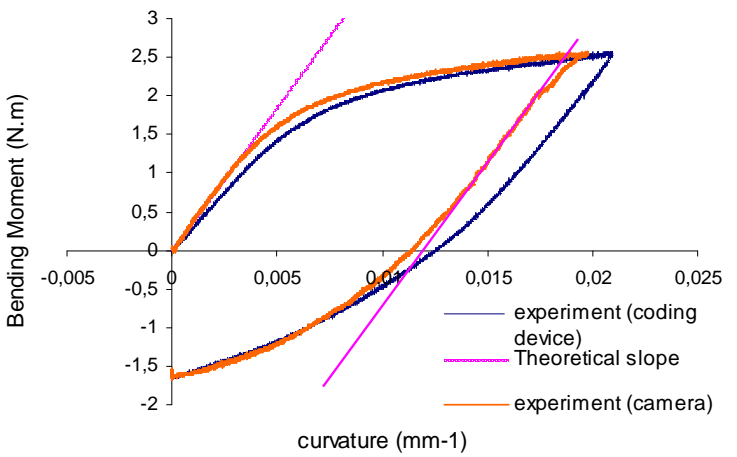

Figure 5: Moment-Curvature diagram

The curves illustrated in figure 8 show that, because of the global interactions and frictions within the equipment of the device, the curves obtained by the coding device give wrong results. Nevertheless, the curvature obtained by the camera gives accurate results because the elastic slope of the curve fit the theory.

\subsection{STRESS-STRAIN LAW IDENTIFICATION}

The identification had first been done assuming an isotropic hardening law of Voce. Since the reverse bending moment is not correctly modelled, a second identification with a Lemaitre and Chaboche combined hardening law has been done [8].

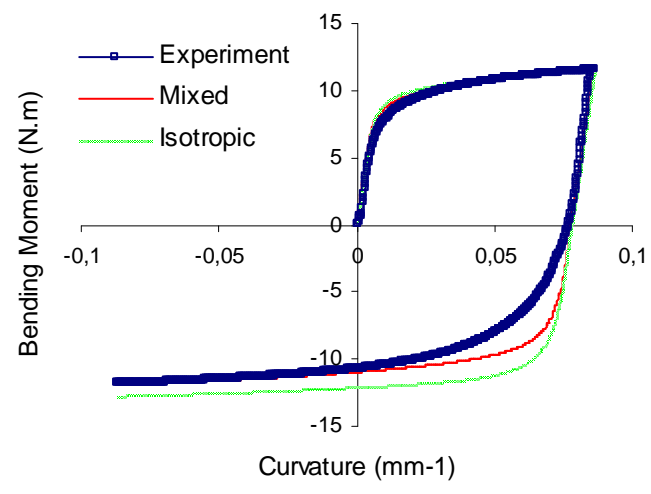

Figure 6: Moment - curvature diagram

\section{COMPLETE PROCESS ANALYSIS AND COMPARISON OF THE DIFFERENT MODELS}

\subsection{BOUNDARY VALUES}

The boundary values imposed in both problems are only the initial and final bending moments of the sheet. In the process, these moments depend on the force imposed in the sheet before and after the leveller. They are nearly zero.

\subsection{RESULTS}

The three following figures show the bending moment of the sheet, the position of the neutral line and the strain of the outer fiber for a 9-roll leveller. The material in this study is a standard mild steel. 


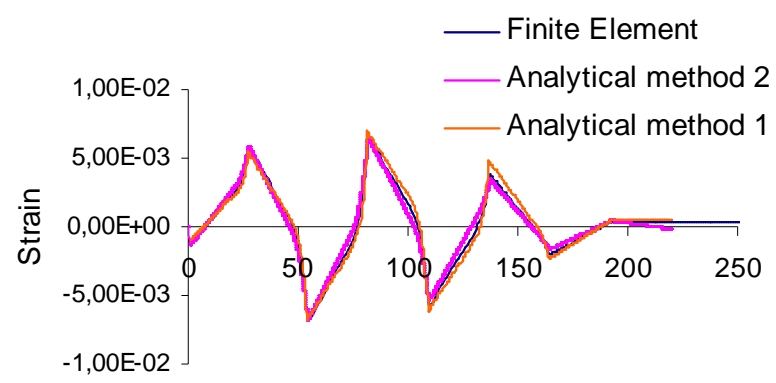

Sheet location $(\mathrm{mm})$

Figure 7: Bending moment of the sheet

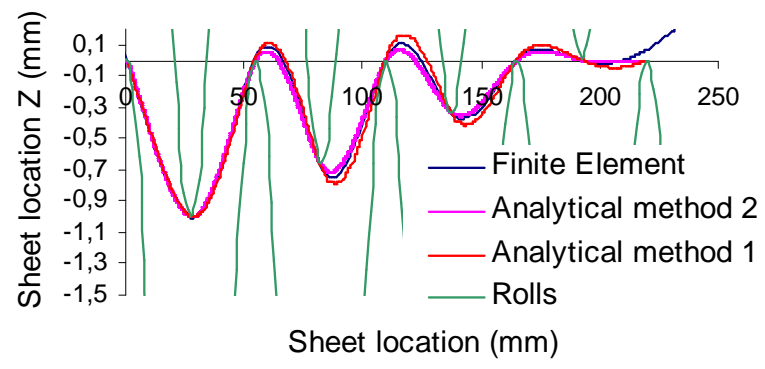

Figure 8: Position of the neutral line of the sheet

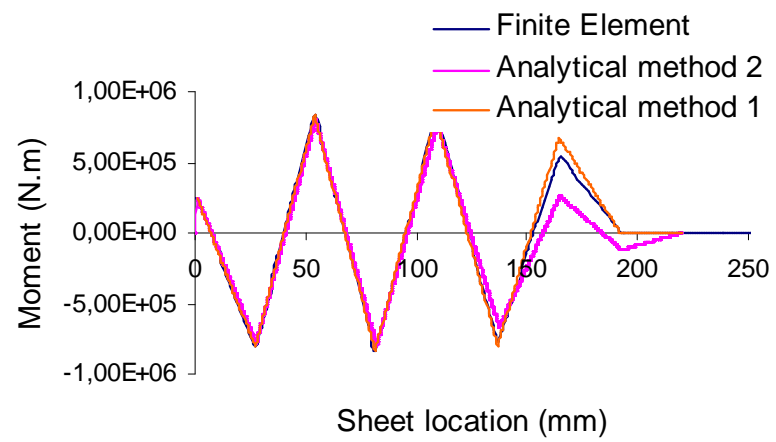

Figure 9: Strain of the surface layer of the sheet

The results seem almost identical even if the methods are different.

\subsection{PRECISION AND TIME COMPUTATION}

The next table shows the differences between the three most important values. All the models are equivalent in terms of strength and maximum strain. However, the residual sheet strains are not equivalent. The analytical model 2 predicts inaccurate residual strains.

\section{Table 1: Comparison of models predictions}

\begin{tabular}{cccc}
\hline & $\begin{array}{c}\text { Finite } \\
\text { element } \\
\text { model }\end{array}$ & $\begin{array}{c}\text { Analytical } \\
\text { model 1 }\end{array}$ & $\begin{array}{c}\text { Analytical } \\
\text { model 2 }\end{array}$ \\
\hline $\begin{array}{c}\text { strength of the } \\
\text { sheet rolls on }\end{array}$ & $334 \mathrm{kN}$ & $347 \mathrm{kN}$ & $295 \mathrm{kN}$ \\
\hline Maximum strain & $6.28 \mathrm{e}-3$ & $6.83 \mathrm{e}-3$ & $6.33 \mathrm{e}-3$ \\
\hline $\begin{array}{c}\text { Residual sheet } \\
\text { strain }\end{array}$ & $3.42 \mathrm{e}-4$ & $4.7 \mathrm{e}-4$ & $-1.94 \mathrm{e}-4$ \\
\hline
\end{tabular}

Table 2 shows the differences between the simulation computed times for a priori quite similar models. Both analytical models are faster than the finite element one. Nevertheless, the "Analytical model 2" is even faster.

\section{Table 2: Simulation computation time}

\begin{tabular}{ccc}
\hline $\begin{array}{c}\text { Finite element } \\
\text { model }\end{array}$ & Analytical model 1 & Analytical model 2 \\
\hline $7 \mathrm{~h} 30^{\prime}$ & $1 \mathrm{~h} 30^{\circ}$ & $20^{\prime}$ \\
\hline
\end{tabular}

\section{CONCLUSIONS}

In this paper, we developed and compared three models for roll levelling operations, a 2-dimensional finite element model and two analytical models. The analytical model 2 is clearly the fastest in terms of calculation speed. Nevertheless, the analytical model 1 is a good compromise between precision and speed calculation.

A specific experimental testing set-up, SOFT (Sheet Oscillatory Flexion Test), has been designed and used to determine the mechanical response of steel sheets for the loading modes of the process. First results in terms of materials parameters identification have been presented.

\section{REFERENCES}

[1] J.Y. Bourgon, D. Dreistadt, O. Guillard, L. Irastorza, Levelling: Modelling and industrial applications, Cahiers d'informations techniques de la revue de métallurgie, 1993, vol. 90, $\mathrm{n}^{\circ} 4$, [Note(s): IV, VI, VII, 537-544 [11 p.]]

[2] K. von. Ploetz, Study of levelling of sheets. Thesis, Leoben University, 1973.

[3] E. Doege, R. Menz, S. Huinink, Analysis of the levelling process based upon an analytic forming model, CIRP Annals - Manufacturing Technology, Volume 51, Issue 1, 2002, Pages 191-194.

[4] Kee-Cheol Park, Sang-Moo Hwang, Development of a Finite Element Analysis Program for Roller Leveling and Application for Removing Blanking Bow Defects of Thin Steel Sheet. ISIJ International, Vol. 42 No. 9, pp 990-999. 2002.

[5] 2D Forging Simulation Software, Transvalor S. A., 2005.

[6] Marciniak Z., Duncan J.L., The mechanics of sheet metal Forming, 1992.

[7] G. Arnold, O. Hubert, R. Billardon, Inverse Identification of elasto-plastically constitutive law of thin sheets with a pure bending test, XVéme Congrès Français de Mécanique, 3-7 septembre 2001.

[8] J. Lemaître, J.L. Chaboche, Mechanic of Solid Materials, Cambridge University Press, Cambridge, U.K., 1990 